\title{
AGE-DEPENDENT SURVIVAL OF ISLAND VS. MAINLAND POPULATIONS OF TWO AVIAN SCAVENGERS: DELVING INTO MIGRATION COSTS
}

Ana Sanz-Aguilar ${ }^{1,2 *}$, Félix De Pablo ${ }^{3}$ \& José Antonio Donázar ${ }^{1}$

${ }^{1}$ Department of Conservation Biology, Estación Biológica de Doñana (CSIC), Américo Vespucio s/n, E-41092 Sevilla, Spain

${ }^{2}$ Population Ecology Group, Instituto Mediterráneo de Estudios Avanzados, IMEDEA (CSICUIB), Miquel Marqués 21, E-07190 Esporles, Islas Baleares, Spain

${ }^{3}$ Institut Menorquí d'Estudis (IME), Camí Vell des Castell 28, 07702 Mahón (Menorca), Islas Baleares, Spain

*Corresponding Author: Ana Sanz-Aguilar, Estación Biológica de Doñana (CSIC), Américo Vespucio s/n, E-41092 Sevilla, Spain, E-mail: ana.sanzaguilar@ebd.csic.es

Author Contributions: ASA, FDP and JAD conceived and designed the study. FDP collected the data. ASA analyzed the data. ASA, FDP and JAD wrote the manuscript. 
2 Large terrestrial long-lived birds (including raptors) are typically sedentary on islands, even when they are migratory on the mainland. Density-dependent variation in the age at first breeding has been described as responsible for the long-term persistence of long-lived bird populations on islands. However, sedentary island populations may also benefit from higher survival rates derived from the absence of migration costs, especially for young individuals. Thus, sedentary island populations can mimic a natural experiment to study migration costs. We estimated the age-dependent survival of two sedentary raptors on Menorca Island (Egyptian vultures Neophron percnopterus and red kites Milvus milvus) and compared these estimates with those reported for other migratory and sedentary populations. In Menorca, Egyptian vultures, but not red kites, showed low levels of human-related mortality resulting in extremely high survival probabilities, probably due to different diet choices and behavioral patterns. Juvenile Egyptian vultures and red kites in the studied population had lower survival probabilities than adults. This difference, however, was smaller than those reported for mainland migrant populations, which showed a lower juvenile survival rate. In fact, betweenpopulation comparisons suggested that survival of the young in migrant populations may be triggered by mortality factors in wintering areas. In contrast, adult survival may respond to mortality factors in breeding areas. Our results suggest that raptor species that become sedentary on islands may benefit from higher pre-breeder survival prospects in comparison

Keywords: Neophron percnopterus, Milvus milvus, multievent, radiotracking, demography. 
How isolated populations of long-lived terrestrial vertebrates persist in the long-term

is a central topic in research in ecology, evolution and the conservation of insular systems (Morris and Doak 2002; Whittaker and Fernández-Palacios 2007). Although numerous animal populations have become extinct or are currently threatened as a consequence of human activities, intrinsic traits of animal species are strongly associated with extinction risks (Boyer 2010). Conservative life-history strategies distinctive of long-lived organisms (i.e., long generation time) involve higher extinction risks when persecution or predation occurs (Owens and Bennett 2000). Long-lived animals typically present low fecundity, high survival, a delayed accession to reproduction and age-dependent vital rates (i.e., survival and productivity) (Newton 1989; Forslund and Pärt 1995). Consequently, their population growth rate is highly sensitive to changes in both adult (Sæther and Bakke 2000) and cumulative prebreeder survival (Sergio et al. 2011). Adult survival is generally higher and less variable than juvenile survival (Sæther and Bakke 2000; Sanz-Aguilar et al. 2014). Juveniles have to deal with inexperience in foraging skills (Greig et al. 1983) and territory defense or poorer competitive abilities (Forero et al. 1999). In addition, long-lived terrestrial animals show limited dispersal opportunities and small population sizes, which increase their chances of extinction through environmental and/or demographic stochasticity processes (Lande 1988; Morris and Doak 2002; Whittaker and Fernández-Palacios 2007).

Within this scenario, it may be hypothesized that the persistence of island populations can be linked to fundamental changes in key demographic parameters. Additionally, island populations represent natural experiments in which dispersal is limited (Whittaker and Fernández-Palacios 2007). In this respect, it is key that large, insular terrestrial long-lived birds with deferred sexual maturity are generally sedentary (raptors and ciconiiforms) in contrast with those populations of the mainland, which tend to be migratory (Donázar et al 
2005; Ferrer et al. 2011). Island populations are especially subject to inbreeding depression and/or density-dependence problems (Lande 1988; Brouwer et al. 2009). It has been proposed that sedentary island birds can gain experience earlier and recruit at younger ages than their migratory counterparts facilitating their persistence (Ferrer et al. 2004, 2011). However, whether sedentary island populations benefit from the absence of migration costs in terms of survival is unexplored (Sanz-Aguilar et al. 2012). In fact, juvenile and adult survival in several migratory long-lived raptor species has been shown to be influenced by both migration and environmental conditions at wintering grounds (Grande et al. 2009; Mihoub et al. 2010; Klaassen et al. 2014; Sergio et al. 2014). Migration between wintering and breeding grounds is recognized as a critical period for the survival of young birds (Mihoub et al. 2010; Sanz-Aguilar et al. 2012; Sergio et al. 2014). By using the most seasonally suitable habitats, individuals are expected to improve their fitness by increasing future fecundity and/or survival (Berthold 2001). However, the benefits of migration may be balanced by costs associated with the migratory process (Alerstam et al. 2003), and survival can be jeopardized by adverse environmental conditions during migration and/or at wintering areas (Schaub et al. 2005; Newton 2006; Grande et al. 2009; Carrete et al. 2013; Klaassen et al. 2014; Sergio et al. 2014). Moreover, studies on partial migratory long-lived species such as the white stork Ciconia ciconia or the greater flamingo Phoenicopterus roseus revealed an increased juvenile survival for resident or short-distance wintering individuals (Schaub et al. 2004; Sanz-Aguilar et al. 2012), although the opposite result was found in merlins (Falco columbarius) (Warkentin et al. 1990).

The aim of this study is to describe the relationship between age-dependent survival and sedentary/migratory habits of two long-lived scavenger raptors inhabiting island (i.e., sedentary populations) and mainland areas (i.e., migrant populations). The selected species are the Egyptian vulture Neophron percnopterus, and the red kite Milvus milvus, a globally 
endangered and near threatened species, respectively (BirdLife International 2014). Egyptian vultures from mainland European populations are long-distance migrants wintering in the sub-Saharan Sahel region (López-López et al. 2014). Red kites are resident in most of their Western European range, but birds from northeastern and central Europe typically winter in the south; mainly in Iberia and France (Schaub 2012). On the contrary, the two species are resident on islands both in the Mediterranean (Balearic Islands) and in Macaronesia (Canary and Cape Verde archipelagos, Donázar et al. 2002, 2005). We estimate the survival rates of the species on Menorca Island, a small Mediterranean island, and compare the obtained values with those reported for other sedentary populations (Mallorca and Canary islands, Donázar et al. 2002; Tavecchia et al. 2012; Tenan et al. 2012) and mainland migrant populations (continental Spain and Switzerland, (Grande et al. 2009; Kéry and Schaub 2012; Sanz-Aguilar et al. 2015). Our main hypothesis is that survival rates should consistently differ between island and mainland populations of the two species due to the absence of migration costs in island populations. We specifically predict that: 1) resident populations inhabiting islands should present a higher survival rate; 2) because migration imposes higher costs during the first years of life, differences in survival rates should be higher for the immature fraction of the populations; 3) given that Egyptian vultures have a later recruitment and lower fecundity than red kites (Newton et al. 1989; Carrete et al. 2009; Cortés-Avizanda et al. 2009; Tenan et al. 2012), we expect a lower variability of survival between age classes and between populations for Egyptian vultures (Sæther and Bakke 2000).

\section{METHODS}

\section{$\underline{\text { Study species }}$}

Egyptian vultures and red kites are highly opportunistic species, foraging on small wild prey and on carcasses of small and medium-sized animals (Donázar 1993). Non-breeders typically aggregate around predictable food resources (e.g., landfills or vulture restaurants) 
(Donázar et al. 1996; López-López et al. 2013). Given their larger body size, Egyptian vultures can feed on larger items than red kites. Egyptian vultures are able to reproduce at three years of age (own data) but typically recruit from five years of age onwards (Carrete et al. 2009; Sanz-Aguilar et al. 2015), whereas red kites, able to breed in their first year, typically recruit at two-three years of age (Newton et al. 1989; Tenan et al. 2012). The two species in both island and mainland populations are subject to the same key anthropogenic mortality causes: poisoning, electrocution and direct persecution (Donázar et al. 2002; Hernández and Margalida 2009; Knott et al. 2009; Smart et al. 2010; Tavecchia et al. 2012). Additionally, on mainland populations wind-farm collision is an important mortality factor (Carrete et al. 2009; Schaub 2012; Bellebaum et al. 2013; Sanz-Aguilar et al. 2015).

\section{$\underline{\text { Study area and data collection }}$}

The study was carried out on Menorca Island (Balearic Archipelago, 3958'00' $\mathrm{N}$ $4^{\circ} 05^{\prime} 00^{\prime}$ E, $701 \mathrm{Km}^{2}$ ) (Fig. 1). The Egyptian vulture population comprised around 50 breeding pairs in 1989, which declined to 39 pairs in 1999 and increased again to 51 in 2004 (authors' own data). From 2004 to 2014, the breeding population was stable at around 50 pairs (authors' own data). Egyptian vultures are mainly distributed on ravines and marine cliffs on the eastern part of the island (De Pablo 2002). 135 breeding pairs of red kites bred on the island in the mid-1980's, but an intense decline due to poisoning and electrocution led to a minimum number of 6 breeding pairs in 1998 (De Pablo 2004). Since then, the population has increased to 27 breeding pairs in 2014 distributed throughout the island (authors' own data). Exceptional individual exchanges with the neighboring Mallorca Island have been recorded for the red kite (3 individuals) but not for the Egyptian vulture (authors' own data).

From 1998 to 2005, 45 first-year, 2 second-year and 8 adult Egyptian vultures of unknown age were captured and marked with PVC rings with a unique alpha-numeric code 
allowing for long-distance identification and equipped with a radiotransmitter (TW3 2xAA and TW3 AA, BIOTRACKS LTD) mounted on a Teflon backpack harness. Transmitters had a life expectancy of 3-7 years and weighed $<5 \%$ of bird body weight. Additionally, 21 firstyear Egyptian vultures were only marked with PVC rings. Individual age was determined on the basis of plumage characteristics (Cramp and Simmons 1977). Resightings of live individuals without active radio-signals $(\mathrm{n}=15)$ and/or without radiotransmitters $(\mathrm{n}=8)$ were recorded during population monitoring, and dead individuals with $(\mathrm{n}=5)$ and without radiotransmitters $(\mathrm{n}=3)$ were recovered.

From 1999 to 2010, 153 fledgling red kites were marked and equipped with a radiotransmitter (TW3 AA BIOTRACKS LTD) mounted on a Teflon backpack harness. Transmitters had a life expectancy of 2-4 years and weighed $<5 \%$ of bird body weight. Individuals of both species were radio-tracked weekly until the end of battery life, the loss of the radio signal, their death and/or the end of the study (December 2012). When a bird radio-signal was lost, we flew the entire island in a small aircraft trying to relocate marked birds. Moreover, the radio-signal frequencies of lost individuals were also tracked by a research team on the neighboring island of Mallorca, which allowed the location and tracking of 3 red kites that moved to Mallorca. 73 red kites were recovered dead during the study period. Causes of mortality were determined by necropsy and pathology procedures (Hernández and Margalida 2009). They were classified as follows: poisoning, electrocution, wind farm collision, natural deaths (including drowned birds and birds with broken bones or muscle injuries) and unknown cause (when decomposition of the carcass did not allow a precise determination of cause of death).

Survival modeling

To take advantage of all the available information collected in the field we designed two capture-recapture multievent models able to combine multiple sources of information to 
estimate individual survival (Pradel 2005). For the Egyptian vultures, the multievent model (see model details in Online Resource 1) allowed the combination of radiotracking, resighting and recovery data. Individuals with active radiotransmitters presented perfect resighting and recovery probabilities $(=1)$, whereas those without active radio signal detection and recovery were estimated by the model proposed in Tavecchia et al. (2012). The model allowed the estimation of simultaneous survival and radio signal functioning probabilities (Tavecchia et al. 2012) (see details in Online Resource 1). As only 8 vultures were recovered dead (one adult by poisoning, 2 first-year individuals due to natural causes, and 2 first-year individuals, 2 subadults and 1 adult due to unknown causes), we did not take into account different mortality causes in our multievent model. Given that goodness-of-fit (GOF) has not yet been developed for multievent models, capture-recapture analysis of Egyptian vulture data began with the assessment of the GOF of the Arnason-Schwarz multisite model to the data (Pradel et al. 2005) using program U-CARE 2.3.2 (Choquet et al. 2009a). We began our model selection with a general model considering 8 age classes for radio signal functioning transition parameters and 7 age classes for survival transition parameters, which were selected on the basis of previous knowledge of the species (i.e., differences between 6 age classes found by Grande et al. (2009) and the maximum expected radiotransmitter battery life: 7 years). We first simplified the structure of the radiotransmitter functioning parameter and then modeled survival probabilities as a function of age. We considered different age structures (levels) and models with a linear as well as quadratic function of age (covariates) on survival.

As very few red kites were identified using their ring code once the radio signals were lost $(n=2)$ we discarded these observations and used known fate radiotracking data on live and dead encounters to estimate individual survival with a specific multievent model. This multievent model allowed the combination of live radiotracking with recovery data specifying the different causes of mortality (Tavecchia et al. 2012) (see details in Online Resource 2). As 
we only used known fate data (i.e., radiotracking) for red kites, no GOF was necessary (White and Burnham 1999). We limited the maximum number of age classes considered to three (juveniles “i.e., first year", subadults "i.e., second year" and adults "i.e., from third year onwards") because of the low numbers of observations of individuals older than four years due to the radiotransmitter battery life and based on previous knowledge of the species (Smart et al. 2010; Kéry and Schaub 2012; Schaub 2012; Tavecchia et al. 2012; Tenan et al. 2012). We first tested differences in survival probabilities and then differences in mortality causes between age classes.

Models were built and fit to the data using the program E-SURGE 1.6.3 (Choquet et al. 2009b). Model selection was based on Akaike's Information Criterion adjusted for the effective sample size, AICc (Burnham and Anderson 2002). In addition, for each model $j$, we calculated the Akaike weight, $w_{j}$, as an index of its relative plausibility (Burnham and Anderson 2002). Estimates were obtained by model averaging in which each model contributed to the final estimate according to its $w_{j}$ (Burnham and Anderson 2002).

\section{Comparison of survival with other populations}

We investigated the extent of age-dependent survival differences among different populations with available survival estimates (and SE) of the studied species in other insular and mainland regions of Western and central Europe and Macaronesia (Fig. 1-2). We used Ztests (Zar 1999), as estimates across datasets were independent.

For the Egyptian vulture we used the estimates obtained for the migrant Ebro population $(\phi$ age $1-2=0.72(0.02), \phi$ age $3-4=0.78(0.03), \phi$ age $5=0.60(0.05), \phi$ breeders $=0.83$ (0.02), (Grande et al. 2009)), the migrant Andalusia population ( $\phi$ non-breeders age $1-5=0.73(0.04), \phi$ breeders $=0.94(0.04),($ Sanz-Aguilar et al. 2015)) and the resident Canary population $(\phi$ age $1-5=0.887(0.045), \phi$ age $>5 \&$ breeders $=0.897(0.098)$, (Donázar et al. 2002)). 
We compared red kite survival probabilities obtained in this study with those of the neighboring population of Mallorca $(\phi$ age $1=0.72(0.08), \phi$ age $2=0.82(0.09), \phi$ age $>2=0.79$ (0.09), (Tavecchia et al. 2012)), and the partial but mainly migratory Swiss population ( $\phi$ age $1=0.41(0.14), \phi$ age $2=0.66(0.07), \phi$ age $>2=0.84(0.03)$, (Kéry and Schaub 2012)).

\section{RESUlTS}

\section{Egyptian vulture survival}

The overall goodness-of-fit test of the Arnason-Schwarz multisite model was not statistically significant $\left(\chi^{2}=4.263\right.$, d.f. $\left.=19, \mathrm{p}=0.999\right)$. We began model selection by testing different age structures in radio signal functioning probabilities (models Mv 1-Mv 6, Table 1). The structure of the radio signal functioning parameter that minimized AICc considered 8 age classes (i.e., 8 years) and a linear decreasing trend over time in the probabilities of radiotransmitter functioning (model Mv 4, Table 1). More complex or simpler structures did not reduce AICc: no radiotransmitter functioned longer than 7 years and the model predicted an accumulated probability of radiotransmitter functioning in its $8^{\text {th }}$ year of 0 (results not shown). We selected the structure of model Np4 to test for differences in survival between age classes (Models Mv 4, Mv 7- Mv 12, Table 1) and to test for linear and quadratic age effects on survival (Models Mv 13 - Mv 14, Table 1). The best model in terms of AICc included 2 age classes on survival probabilities: a differential survival between first-year and older birds (Model Mv 11, Table 1). However, this model was close in terms of AICc to other models (Models Mv 11-Mv 13). Model averaged survival estimates (and SE) were: $\phi$ nonbreeders age $1=0.92(0.04), \phi$ non-breeders age $2=0.99(0.01), \phi$ non-breeders age $3=0.97$ (0.02), $\phi$ non-breeders age $>3=0.99(0.01)$, and $\phi$ breeders of unknown age $=0.98(0.02)$ (Fig. 2). Resighting probabilities ranged from 0 to 0.31 (results not shown) and recovery probability was $0.43(\mathrm{SE}=0.33)$. 
The modeling of age effects on survival probabilities of red kites showed that firstyear birds (i.e., juveniles) presented a different survival rate than older birds because the models considering no age-effects (Model Mm 4, Table 2) or no differences between juveniles and subadults (2 years old) were rejected in terms of AICc (Model Mm 3, Table 2). The models considering equal survival of adults (older than 2 years old) and subadults (Model Mm 2, Table 2) or full age differences (Model Mm 1, Table 2) were close in terms of AICc. Consequently, we used both structures of survival (Model Mm 1-Mm 2, Table 2) to model the probabilities of the different mortality causes. The best models included differences in mortality causes between young birds (including juveniles and subadults) and adults (Models Mm 6 and Mm 9, Table 2). However, models considering no age effects on the probabilities of dying due to the different mortality causes were also close in terms of AICc (Models Mm 7 and Mm 10, Table 2). Model averaged survival estimates (and SE) were: $\phi$ juveniles (age $1)=0.54(0.04), \phi$ subadults $($ age 2$)=0.83(0.04)$ and $\phi$ adults $($ age $\geqslant 3)=0.84(0.05)$ (Fig. 2). Model averaged estimates of mortality causes showed that birds mainly died by poisoning, followed by electrocution, unknown and natural causes and wind farm collision (Fig. 3). Although confidence intervals overlap, mortality by poisoning seemed to be higher for adults than for subadults and juveniles (Fig. 3).

\section{Comparison of survival with mainland and other island populations}

Non-breeding Egyptian vultures from sedentary populations (aged 1 to 7), Menorca and Canary, survived significantly better than individuals from the Ebro or the Andalusia migrant populations (Fig. 2, Table 3). Non-significant differences in breeder survival between adult breeders from Andalusia, Menorca and Canary were found but breeders from the Ebro population had a lower survival than breeders from Menorca and Andalusia (Fig. 2, Table 3). Survival in the migrant populations (Andalusia and Ebro) only differed significantly for non- 
breeders aged 5 and breeders, being higher for the Andalusia population (Fig. 2, Table 3).

Survival in the resident populations (Menorca and Canary) only differed significantly for nonbreeders aged 2, 4 and 5, being higher for the Menorca population (Fig. 2, Table 3).

We did not find significant differences in red kite adult survival (birds older than 2 years old) between the three considered populations (Fig. 2, Table 4). Subadult survival in Menorca birds was significantly higher than in the Swiss population and similar to survival on Mallorca Island, which presented intermediate values and no differences from the Swiss population (Fig. 2, Table 4). Juvenile survival was significantly higher in Mallorca than in Menorca or Swiss populations, which showed no significant differences (Fig. 2, Table 4).

DISCUSSION

Our study demonstrates that insular sedentary populations of long-lived birds had higher survival rates, especially among young birds, than their mainland migrant counterparts. Moreover, these differences were consistent among two different species inhabiting Mediterranean and Macaronesian archipelagos. This result is in agreement with the observed higher survival rates of resident and short-distance migrant individuals among partial migratory mainland populations of other long-lived birds such as white storks (Schaub et al. 2004), greater flamingos (Sanz-Aguilar et al. 2012) and spoonbills Platalea leucorodia leucorodia (Lok et al. 2013). In fact, no density-dependent effects on the survival of the Seychelles warbler Acrocephalus sechellensis (Brouwer et al. 2009) or survival differences between resident populations of blue tits Parus caeruleus on Corsica Island and the French mainland (Blondel et al. 1992) were found. This suggests that migratory behavior may play a more important role in avian survival than insularity per se.

Age-related improvement in survival expectancies is typical among long-lived birds, such that juveniles have higher mortality rates than adults (Newton 1989). Accordingly, we found that juvenile (i.e., first-year) Egyptian vultures and red kites in the studied population 
had lower survival probabilities than adults. The relative difference between juvenile and adult breeder survival on Menorca Island, however, was smaller (Egyptian vultures $=5 \%$, red kites $=36 \%$ ) than those reported for migrant populations (Andalusia Egyptian vultures $=22 \%$, Ebro Egyptian vultures $=12 \%$, Swiss red kites=52\%) (Grande et al. 2009; Kéry and Schaub 2012; Sanz-Aguilar et al. 2015). Similarly, and in accordance with the results obtained for the studied population, sedentary populations of Egyptian vultures in the Canary Islands and red kites on Mallorca Island also showed small differences between juvenile and adult survival (1\% and 9\%, respectively, (Donázar et al. 2002; Tavecchia et al. 2012)). In summary, age had a milder influence on survival rates in sedentary island populations because of the higher survival probabilities shown by the youngest fraction of the populations.

Egyptian vultures are more long-lived and have a lower fecundity than red kites. Survival differences between age classes were lower for the Egyptian vulture than for the red kite (see above), which is in accordance with the life-history fast-slow continuum (Sæther and Bakke 2000). The red kite population on Mallorca Island, however, showed small survival differences between juveniles and adults (9\%, Tavecchia et al. 2012). High juvenile survival rates have been reported for sedentary raptor populations supplemented with food (Sarrazin et al. 1994; Oro et al. 2008) because it can buffer the effect of illegal poisoning and other mortality factors (Oro et al. 2008, 2013; Tavecchia et al. 2012). We are confident that this was the most plausible explanation for the high survival rate of juvenile red kites in Mallorca (Tavecchia et al. 2012; Tenan et al. 2012). In fact, these rates were the highest ever reported for this species (see Newton et al. 1989; Knott et al. 2009, Smart et al. 2010; Kéry and Schaub 2012; Bellebaum et al. 2013). On the contrary, on Menorca Island there are no supplementary feeding programs. This could explain the differences in juvenile survival between neighboring islands even when the relative incidence of human-induced mortality factors (poisoning and, to a lesser extent, electrocution) was very similar (Tavecchia et al. 2012; Tenan et al. 2012). 
That said, it should be noted that even given the high levels of human-induced mortality, juvenile and subadult survival of red kites in both Balearic islands (Mallorca and Menorca) were higher than those found for individuals from the Swiss migrant population (Kéry and Schaub 2012), which is not affected by illegal poisoning in its breeding area (Knott et al. 2009).

Non-breeding Egyptian vultures in Menorca showed higher survival rates than in any other studied population (Donázar et al. 2002; Grande et al. 2009; Sanz-Aguilar et al. 2015). The survival differences between island populations may be due to additional mortality factors (causalities with power lines) heavily affecting Egyptian vultures at Canary Islands (Donázar et al. 2002). Contrary to red kites, Egyptian vultures in Menorca were scarcely affected by non-natural human-related mortality. This may be due to different non-exclusive factors: 1) red kites are distributed throughout the island whereas Egyptian vultures are concentrated on the eastern side where illegal poisoning is less common (authors' own observations); 2) the diet of Egyptian vultures relies more heavily on livestock carcasses and less so on small game than red kites (Congost and Muntaner 1974; authors' own data); and 3) Egyptian vultures use trees and cliffs instead of power lines for communal roosting (Congost and Muntaner 1974; authors' own data).

In contrast to juvenile survival, differences in adult/breeder survival between migrant populations were probably more closely related to local human-related mortality factors in breeding areas (Carrete et al. 2009; Hernández and Margalida 2009; Smart et al. 2010; Schaub 2012). There is no doubt that long-distance migration entails costs (Alerstam et al. 2003), including mortality during migration (Newton 2006) and/or at wintering areas (Schaub et al. 2005; Sergio et al. 2011). However, migratory mortality costs may be much more important for young and inexperienced individuals (Mihoub et al. 2010; Sanz-Aguilar et al. 2012; Sergio et al. 2014). In fact, Egyptian vultures from the Andalusia and Ebro breeding 
populations, showed differences in adult survival but not in juvenile and pre-breeding survival. Pre-breeder survival was probably dependent on environmental conditions in their common African wintering areas thus equally affecting individuals from all of the Iberian populations (Grande et al. 2009; Carrete et al. 2013; Sanz-Aguilar et al. 2015).

Small sedentary populations on islands face reduced fitness due to inbreeding depression (Lande 1988). Genetic diversity has been shown to negatively affect recruitment (i.e., delayed reproduction) and breeding success in the Egyptian vulture in the Canary Islands (Agudo et al. 2012). Similarly, the species also presents a very low breeding success on Menorca Island (authors' own data). However, these detrimental effects on productivity may be compensated for by high survival expectancies such as those demonstrated by our results. This fact, in combination with an earlier age at first reproduction among sedentary long-lived birds on islands (Ferrer et al. 2011), may facilitate their persistence and be responsible for the very high densities reached in populations without human-related mortality (Bannerman et al. 1968; De Pablo 2004; Gangoso et al. 2013). In fact, there are numerous small populations of raptors on islands that have persisted with low numbers for at least more than a century (Bannerman et al. 1968; Walter 1990) and even the studied population of red kites is recovering from a minimum population size of 6 breeding pairs. For its part, the Egyptian vulture population on Menorca has remained stable around 50 breeding pairs over the last 10 years (which is the maximum population size ever recorded on this island, authors' own data). None of the vultures marked as young were observed breeding during the study period, which also suggests that density-dependence processes influencing recruitment are acting in this population (Ferrer et al. 2011). In conclusion, although small populations are always subject to environmental and demographic stochasticity effects, our study highlights the potential of persistence of long-lived raptors on islands due to their high survival prospects in the absence of human-related mortality factors. 


\section{AKNOWLEDGEMENTS}

350

351

352

353

354

355

356

357

358

359

360

361

362

363

364

365

366

367

368

369

370

We are grateful to Giacomo Tavecchia for his statistical advice and comments.

\section{FUNDING}

This work was partially funded by projects JCI-2011-09085, CGL2012-40013-C02-01-02, Severo Ochoa Excellence Award (SEV-2012-0262) Ministerio de Economía y

Competitividad, Spanish Government and EU FEDER funds. The Regional Government of Balearic Islands provided permits to capture birds and financed part of the work.

\section{CONFLICT OF INTEREST}

The authors declare that they have no conflict of interest.

\section{ETHICAL APPROVAL}

All applicable institutional and/or national guidelines for the care and use of animals were followed.

\section{REFERENCES}

Agudo R, Carrete M, Alcaide M, Rico C, Hiraldo F, Donázar JA (2012) Genetic diversity at neutral and adaptive loci determines individual fitness in a long-lived territorial bird. Proc $\mathrm{R}$ Soc B Biol Sci 279:3241-3249.

Alerstam T, Hedenström A, Åkesson S (2003) Long-distance migration: evolution and determinants. Oikos 103:247-260.

Bannerman DA, Bannerman WM, Reid-Henry DM (1968) Birds of the Atlantic islands.

Oliver \& Boyd.

Bellebaum J, Korner-Nievergelt F, Dürr T, Mammen U (2013) Wind turbine fatalities approach a level of concern in a raptor population. J Nat Conserv 21:394-400. 
371 Berthold P (2001) Bird migration: a general survey. Oxford University Press, Oxford

372 BirdLife International (2014) IUCN Red List for birds. http://www.iucn.org/

373 Blondel J, Pradel R, Lebreton J-D (1992) Low fecundity insular blue tits do not survive better 374 as adults than high fecundity mainland ones. J Anim Ecol 61: 205-213.

375 Boyer AG (2010) Consistent Ecological Selectivity through Time in Pacific Island Avian 376 Extinctions. Cons. Biol. 24: 511-519.

377 Brouwer L, Tinbergen JM, Both C, Bristol R, Richardson DS, Komdeur J (2009)

378 Experimental evidence for density-dependent reproduction in a cooperatively breeding 379 passerine. Ecology 90:729-741.

380 Burnham KP, Anderson DR (2002) Model selection and multi-model inference: a practical 381 information-theoretic approach. Springer, New York, USA.

382 Carrete M, Sánchez-Zapata JA, Benítez JR, Lobón M, Donázar JA (2009) Large scale risk383 assessment of wind-farms on population viability of a globally endangered long-lived raptor. 384 Biol Conserv 142:2954-2961.

385 Carrete M, Bortolotti GR, Sánchez-Zapata JA, Delgado A, Cortés-Avizanda A, Grande JM, 386 Donázar J (2013) Stressful conditions experienced by endangered Egyptian vultures on 387 African wintering areas. Anim Conserv 16:353-358.

388 Choquet R, Lebreton J, Gimenez O, Reboulet AM, Pradel R (2009a) U-CARE: Utilities for 389 performing goodness of fit tests and manipulating Capture-REcapture data. Ecography $390 \quad 32: 1071-1074$. 
Choquet R, Rouan L, Pradel R (2009b) Program E-SURGE: a software application for fitting multievent models. In: Cooch E, Conroy M, Thomson D (eds) Modeling demographic processes in marked populations. Springer, Berlin, pp 845-865.

Congost J, Muntaner J (1974) Presencia otoñal e invernal y concentración de Neophron percnopterus en la isla de Menorca. Miscelanea Zool 3:151-161.

Cortés-Avizanda A, Ceballos O, Donázar J (2009) Long-term trends in population size and breeding success in the Egyptian Vulture (Neophron percnopterus) in Northern Spain. J Raptor Res 43:43-49.

Cramp S, Simmons K (1977) Birds of the western Palearctic: handbook of the birds of Europe, the Middle East and North Africa. Oxford University Press, Oxford.

De Pablo F (2002) La situación del alimoche, Neophron percnopterus, en las Islas Baleares. Anuari Ornitològic Balears 17:53-57.

De Pablo F (2004) Bases Ecológicas para la elaboración de un plan de recuperación de la población de milanos reales, Milvus milvus. $\mathrm{PhD}$ dissertation. Universidad de Barcelona, Barcelona, Spain.

Donázar J (1993) The Iberian Vultures. Biology and Conservation. JM Reyero, Madrid.

Donázar JA, Ceballos O, Tella JL (1996) Communal roosts of Egyptian vultures (Neophron percnopterus): dynamics and implications for the species conservation. In: Muntaner J, Mayol J (eds) Biología y Conservación de las Rapaces Mediterráneas, 1994 (Monografías n 4), SEO, pp 189-202. 
Donázar JA, Palacios CJ, Gangoso L, Ceballos O, González MJ, Hiraldo F (2002)

412 Conservation status and limiting factors in the endangered population of Egyptian vulture (Neophron percnopterus) in the Canary Islands. Biol Conserv 107:89-97.

414 Donázar JA, Gangoso L, Forero MG, Juste J (2005) Presence, richness and extinction of birds of prey in the Mediterranean and Macaronesian islands. J Biogeogr 32:1701-1713.

Ferrer M, Otalora F, García-Ruiz JM (2004) Density-dependent age of first reproduction as a buffer affecting persistence of small populations. Ecol Appl 14:616-624.

Ferrer M, Bildstein K, Penteriani V, Casado E, de Lucas M (2011) Why birds with deferred sexual maturity are sedentary on islands: a systematic review. PloS One 6:e22056.

Forero MG, Donázar JA, Blas J, Hiraldo F (1999) Causes and consequences of territory change and breeding dispersal distance in the black kite. Ecology 80:1298-1310.

422 Forslund P, Pärt T (1995) Age and reproduction in birds-hypotheses and tests. Trends Ecol 423 Evol 10:374-378.

425 Reinventing mutualism between humans and wild fauna: insights from vultures as ecosystem 426 services providers. Conserv Lett 6:172-179.

427 Grande JM, Serrano D, Tavecchia G, Ceballos O, Díaz-Delgado R, Tella JL, Donázar JA 428 (2009) Survival in a long-lived territorial migrant: effects of life-history traits and ecological conditions in wintering and breeding areas. Oikos 118:580-590. herring gull (Larus argentatus). Anim Behav 31:1237-1243. 
Hernández M, Margalida A (2009) Poison-related mortality effects in the endangered Egyptian vulture (Neophron percnopterus) population in Spain. Eur J Wildl Res 55:415-423.

Kéry M, Schaub M (2012) Bayesian population analysis using WinBUGS: a hierarchical perspective. Academic Press.

Klaassen RH, Hake M, Strandberg R, Koks BJ, Trierweiler C, Exo KM, Bairlein F, Alerstam $\mathrm{T}$ (2014) When and where does mortality occur in migratory birds? Direct evidence from long-term satellite tracking of raptors. J Anim Ecol 83:176-184.

Knott J, Newbery P, Barov B (2009) Action Plan for the Red Kite Milvus milvus in the European Union. BirdLife International for the European Union.

Lande R (1988) Genetics and demography in biological conservation. Science 241:1455-1460.

Lok T, Overdijk O, Piersma T (2013) Migration tendency delays distributional response to differential survival prospects along a flyway. Am Nat 181:520-531.

López-López P, García-Ripollés C, Urios V (2013) Food predictability determines space use of endangered vultures: implications for management of supplementary feeding. Ecol Appl 24:938-949.

López-López P, García-Ripollés C, Urios V (2014) Individual repeatability in timing and spatial flexibility of migration routes of trans-Saharan migratory raptors. Curr Zool 60:642652.

Mihoub J-B, Gimenez O, Pilard P, Sarrazin F (2010) Challenging conservation of migratory species: Sahelian rainfalls drive first-year survival of the vulnerable Lesser Kestrel Falco naumanni. Biol Conserv 143:839-847. 
453

454

455

456

457

458

459

460

461

462

463

464

465

466

467

468

469

470

471

472

473

Morris WF, Doak DF (2002) Quantitative conservation biology. Sinauer Associates

Sunderland, Massachusetts, USA.

Newton I (1989) Lifetime reproduction in birds. Academic Press, London, UK.

Newton I (2006) Can conditions experienced during migration limit the population levels of birds? J Ornithol 147:146-166.

Newton I, Davis PE, Davis JE (1989) Age of first breeding, dispersal and survival of Red Kites Milvus milvus in Wales. Ibis 131:16-21.

Oro D, Margalida A, Carrete M, Heredia R, Donazar J A (2008) Testing the goodness of supplementary feeding to enhance population viability in an endangered vulture. PLoS One 3:e4084

Oro D, Genovart M, Tavecchia G, Fowler MS, Martínez-Abraín A (2013) Ecological and evolutionary implications of food subsidies from humans. Ecol Lett 16:1501-1514.

Owens IPF, Bennett PM (2000) Ecological basis of extinction risk in birds: Habitat loss versus human persecution and introduced predators. Proc Natl Acad Sci USA 97:1214412148.

Pradel R (2005) Multievent: an extension of multistate capture-recapture models to uncertain states. Biometrics 61:442-447.

Pradel R, Gimenez O, Lebreton J (2005) Principles and interest of GOF tests for multistate capture-recapture models. Anim Biodivers Conserv 28:189-204.

Sæther B-E, Bakke $\emptyset$ (2000) Avian life history variation and contribution of demographic traits to the population growth rate. Ecology 81:642-653. 
Sanz-Aguilar A, Bechet A, Germain C, Johnson AR, Pradel R (2012) To leave or not to leave: survival trade-offs between different migratory strategies in the greater flamingo. J Anim Ecol 81:1171-1182.

Sanz-Aguilar A, Tavecchia G, Afán I, Ramírez F, Doxa A, Bertolero A, Gutiérrez-Expósito C, Forero MG, Oro D (2014) Living on the Edge: Demography of the Slender-Billed Gull in the Western Mediterranean. PloS One 9:e92674.

Sanz-Aguilar A, Sánchez-Zapata JA, Carrete M, Benítez JR, Ávila E, Arenas R, Donázar JA (2015) Action on multiple fronts, illegal poisoning and wind farm planning, is required to reverse the decline of the Egyptian vulture in Southern Spain. Biol Conserv 187:10-18.

Sarrazin F, Bagnolini C, Pinna JL, Danchin E, Clobert J (1994) High survival estimates of Griffon Vultures (Gyps fulvus fulvus) in a reintroduced population. Auk 111:853-862.

Schaub M (2012) Spatial distribution of wind turbines is crucial for the survival of red kite populations. Biol Conserv 155:111-118.

Schaub M, Pradel R, Lebreton J-D (2004) Is the reintroduced white stork (Ciconia ciconia) population in Switzerland self-sustainable? Biol Conserv 119:105-114.

Schaub M, Kania W, Köppen U (2005) Variation of primary production during winter induces synchrony in survival rates in migratory white storks Ciconia ciconia. J Anim Ecol 74:656-666.

Sergio F, Tavecchia G, Blas J, López L, Tanferna A, Hiraldo F (2011) Variation in agestructured vital rates of a long-lived raptor: Implications for population growth. Basic Appl Ecol 12:107-115. 
Sergio F, Tanferna A, De Stephanis R, López-Jiménez L, Blas J, Tavecchia G, Preatoni D, Hiraldo F (2014) Individual improvements and selective mortality shape lifelong migratory performance. Nature 515:410-413.

Smart J, Amar A, Sim IM, Etheridge B, Cameron D, Christie G, Wilson JD (2010) Illegal killing slows population recovery of a re-introduced raptor of high conservation concern-The red kite Milvus milvus. Biol Conserv 143:1278-1286.

Tavecchia G, Adrover J, Navarro AM, Pradel R (2012) Modelling mortality causes in longitudinal data in the presence of tag loss: application to raptor poisoning and electrocution. J Appl Ecol 49:297-305.

Tenan S, Adrover J, Navarro AM, Sergio F, Tavecchia G (2012) Demographic consequences of poison-related mortality in a threatened bird of prey. PloS One 7:e49187.

Walter HS (1990) Small viable population: the red-tailed hawk of Socorro Island. Conserv Biol 4:441-443.

Warkentin IG, James PC, Oliphant LW (1990) Body morphometrics, age structure, and partial migration of urban Merlins. Auk 107:25-34.

White GC, Burnham KP (1999) Program MARK: survival estimation from populations of marked animals. Bird Study 46:S120-S139.

Whittaker RJ, Fernández-Palacios JM (2007) Island biogeography: ecology, evolution, and conservation. Oxford University Press, Oxford, UK.

Zar JH (1999) Biostatistical analysis. Prentice Hall. 
Table 1. Modeling of radiotransmitter functioning $(\eta)$, survival $(\phi)$, resighting and recovery probabilities of Egyptian Vultures on Menorca Island. Notation, np: number of parameters; Dev: relative deviance; AICc: Akaike information criterion corrected for sample size; $\triangle \mathrm{AICc}$ : the AICc difference between the current model and that with the lowest AICc value; $w$ : Akaike's weight. Model notation: numbers indicate the number of age classes "a" considered, A indicates a linear age trend and $\mathrm{A}^{2}$ a quadratic age trend. Note that all models considered constant adult survival, constant recovery probabilities and time-dependent resighting probabilities. The model with the lowest AICc is in bold.

\begin{tabular}{llllllll}
\hline Model & $\eta$ & $\phi$ & np & Dev & AICc & $\Delta$ AIC & $w$ \\
\hline Mv 1 & a7 & a7 & 36 & 437.4 & 520.27 & 15.14 & 0.00 \\
Mv 2 & A7 & a7 & 31 & 442.59 & 512.53 & 7.40 & 0.01 \\
Mv 3 & a8 & a7 & 37 & 436.24 & 521.76 & 16.63 & 0.00 \\
Mv 4 & A8 & a7 & 31 & 441.98 & 511.92 & 6.79 & 0.01 \\
Mv 5 & a6 & a7 & 35 & 438.89 & 519.13 & 14.00 & 0.00 \\
Mv 6 & A6 & a7 & 31 & 444.22 & 514.15 & 9.02 & 0.00 \\
Mv 7 & A8 & a6 & 30 & 442.27 & 509.68 & 4.55 & 0.03 \\
Mv 8 & A8 & a5 & 29 & 442.79 & 507.69 & 2.56 & 0.07 \\
Mv 9 & A8 & a4 & 28 & 443.23 & 505.65 & 0.52 & 0.20 \\
Mv 10 & A8 & a3 & 27 & 446.42 & 506.37 & 1.24 & 0.14 \\
Mv 11 & A8 & a2 & $\mathbf{2 6}$ & $\mathbf{4 4 7 . 6 3}$ & $\mathbf{5 0 5 . 1 3}$ & $\mathbf{0 . 0 0}$ & $\mathbf{0 . 2 6}$ \\
Mv 12 & A8 & a1 & 25 & 452.37 & 507.45 & 2.32 & 0.08 \\
Mv 13 & A8 & A7 & 26 & 449.12 & 506.63 & 1.50 & 0.12 \\
Mv 14 & A8 & A 7 & 27 & 447.92 & 507.87 & 2.74 & 0.07 \\
\hline
\end{tabular}


Table 2. Modeling of survival $(\phi)$ and mortality probabilities by different causes $(\omega)$ of red kites on Menorca Island. Notation, np: number of parameters; Dev: relative deviance; AICc: Akaike information criterion corrected for sample size; $\triangle \mathrm{AICc}$ : the AICc difference between the current model and that with the lowest AICc value; w: Akaike's weight. Model notation: $\mathrm{j}=\mathrm{juveniles}($ age 1$), \mathrm{sa}=$ subadults (age 2$),$ ad $=$ adults (age $\geq 3),=$ and $\neq$ indicate no differences and differences between the age classes considered, respectively. The model with the lowest AICc is in bold.

\begin{tabular}{|c|c|c|c|c|c|c|c|}
\hline Model & $\phi$ & $\omega$ & $\mathrm{np}$ & Dev & $\mathrm{AICc}$ & $\triangle \mathrm{AIC}$ & $w$ \\
\hline $\mathrm{Mm} 1$ & $\mathrm{j} \neq \mathrm{sa} \neq \mathrm{ad}$ & $\mathrm{j} \neq \mathrm{sa} \neq \mathrm{ad}$ & 13 & 439.61 & 466.46 & 7.09 & 0.01 \\
\hline $\operatorname{Mm} 2$ & $\mathrm{j} \neq \mathrm{sa}=\mathrm{ad}$ & $\mathrm{j} \neq \mathrm{sa} \neq \mathrm{ad}$ & 12 & 439.88 & 464.61 & 5.24 & 0.03 \\
\hline Mm 3 & $\mathrm{j}=\mathrm{sa} \neq \mathrm{ad}$ & $\mathrm{j} \neq \mathrm{sa} \neq \mathrm{ad}$ & 12 & 453.42 & 478.14 & 18.77 & 0.00 \\
\hline $\mathrm{Mm} 4$ & $\mathrm{j}=\mathrm{sa}=\mathrm{ad}$ & $\mathrm{j} \neq \mathrm{sa} \neq \mathrm{ad}$ & 11 & 460.72 & 483.33 & 23.96 & 0.00 \\
\hline Mm 5 & $\mathrm{j} \neq \mathrm{sa}=\mathrm{ad}$ & $\mathrm{j} \neq \mathrm{sa}=\mathrm{ad}$ & 10 & 443.25 & 463.77 & 4.39 & 0.05 \\
\hline Mm 6 & $\mathbf{j} \neq \mathbf{s a}=\mathbf{a d}$ & $\mathrm{j}=\mathrm{sa} \neq \mathrm{ad}$ & 8 & 443.04 & 459.38 & 0.00 & 0.41 \\
\hline $\mathrm{Mm} 7$ & $\mathrm{j} \neq \mathrm{sa}=\mathrm{ad}$ & $\mathrm{j}=\mathrm{sa}=\mathrm{ad}$ & 6 & 448.36 & 460.56 & 1.18 & 0.23 \\
\hline $\operatorname{Mm} 8$ & $\mathrm{j} \neq \mathrm{sa} \neq \mathrm{ad}$ & $\mathrm{j} \neq \mathrm{sa}=\mathrm{ad}$ & 11 & 442.99 & 465.60 & 6.22 & 0.02 \\
\hline $\operatorname{Mm} 9$ & $\mathrm{j} \neq \mathrm{sa} \neq \mathrm{ad}$ & $\mathrm{j}=\mathrm{sa} \neq \mathrm{ad}$ & 9 & 442.77 & 461.19 & 1.81 & 0.17 \\
\hline $\mathrm{Mm} 10$ & $\mathrm{j} \neq \mathrm{sa} \neq \mathrm{ad}$ & $\mathrm{j}=\mathrm{sa}=\mathrm{ad}$ & 7 & 448.09 & 462.35 & 2.98 & 0.09 \\
\hline
\end{tabular}


Table 3. Comparison of the Egyptian vulture average non-breeder (NB) and breeder (B, aged $\geq 5$ ) survival estimates (Z-test) among the populations of Menorca (ME, sedentary), Andalusia (AN, migratory), Ebro (EB, migratory) and Canary (CA, sedentary). Significant effects (twosided $\mathrm{p}<0.05)$ are in bold.

ME vs. AN ME vs. EB ME vs. CA AN vs. EB AN vs. CA EB vs. CA

\begin{tabular}{lllllll}
\hline NB age 1 & $\mathbf{3 . 5 2}$ & $\mathbf{4 . 5 2}$ & 0.60 & -0.16 & $\mathbf{- 2 . 5 1}$ & $\mathbf{- 3 . 0 2}$ \\
NB age 2 & $\mathbf{6 . 3 0}$ & $\mathbf{1 1 . 9 9}$ & $\mathbf{2 . 0 5}$ & 0.00 & $\mathbf{- 2 . 5 1}$ & $\mathbf{- 3 . 0 2}$ \\
NB age 3 & $\mathbf{5 . 3 5}$ & $\mathbf{5 . 2 4}$ & 1.61 & -1.00 & $\mathbf{- 2 . 5 1}$ & $\mathbf{- 1 . 8 9}$ \\
NB age 4 & $\mathbf{6 . 2 4}$ & $\mathbf{6 . 5 6}$ & $\mathbf{2 . 0 4}$ & -1.00 & $\mathbf{- 2 . 5 1}$ & $\mathbf{- 1 . 8 9}$ \\
NB age 5 & $\mathbf{6 . 2 3}$ & $\mathbf{7 . 5 9}$ & $\mathbf{2 . 0 4}$ & $\mathbf{2 . 0 3}$ & $\mathbf{- 2 . 5 1}$ & $\mathbf{- 4 . 1 4}$ \\
B & 0.81 & $\mathbf{4 . 7 7}$ & 0.80 & $\mathbf{2 . 4 6}$ & 0.41 & -0.67 \\
\hline
\end{tabular}


Table 4. Comparison of the red kite average survival estimates (Z-test) among the populations of Menorca (ME, sedentary), Mallorca (MA, sedentary) and Switzerland (SW, migratory). Significant effects (two sided $\mathrm{p}<0.05$ ) are in bold.

\begin{tabular}{lccc}
\hline & ME vs MA & ME vs SW & MA vs SW \\
\hline Juveniles (age 1) & $\mathbf{- 2 . 0 2}$ & 0.93 & $\mathbf{1 . 9 6}$ \\
Subadults (age 2) & 0.10 & $\mathbf{2 . 2 3}$ & 1.46 \\
Adults (age $\geq 3$ ) & 0.49 & -0.02 & -0.54 \\
\hline
\end{tabular}


Figure 1. Study areas and species. Survival rates were estimated for Egyptian vultures (EV) and red kites (RK) living in 1: Menorca Island. Results were compared with those obtained in other studies from 2: Mallorca Island, 3: Canary Fuerteventura Island, 4: Ebro Valley, 5: Andalusia, 6: Switzerland.

Figure 2. Population specific age-dependent survival estimates (and 95\% CI) of Egyptian vultures (A) and red kites (B). Sedentary populations are denoted with black symbols and migratory populations with empty symbols.

Figure 3. Probabilities of juvenile, subadult and adult red kite mortality (and 95\% CI) by the different causes considered (poisoning, electrocution, collision, natural and unknown causes). 


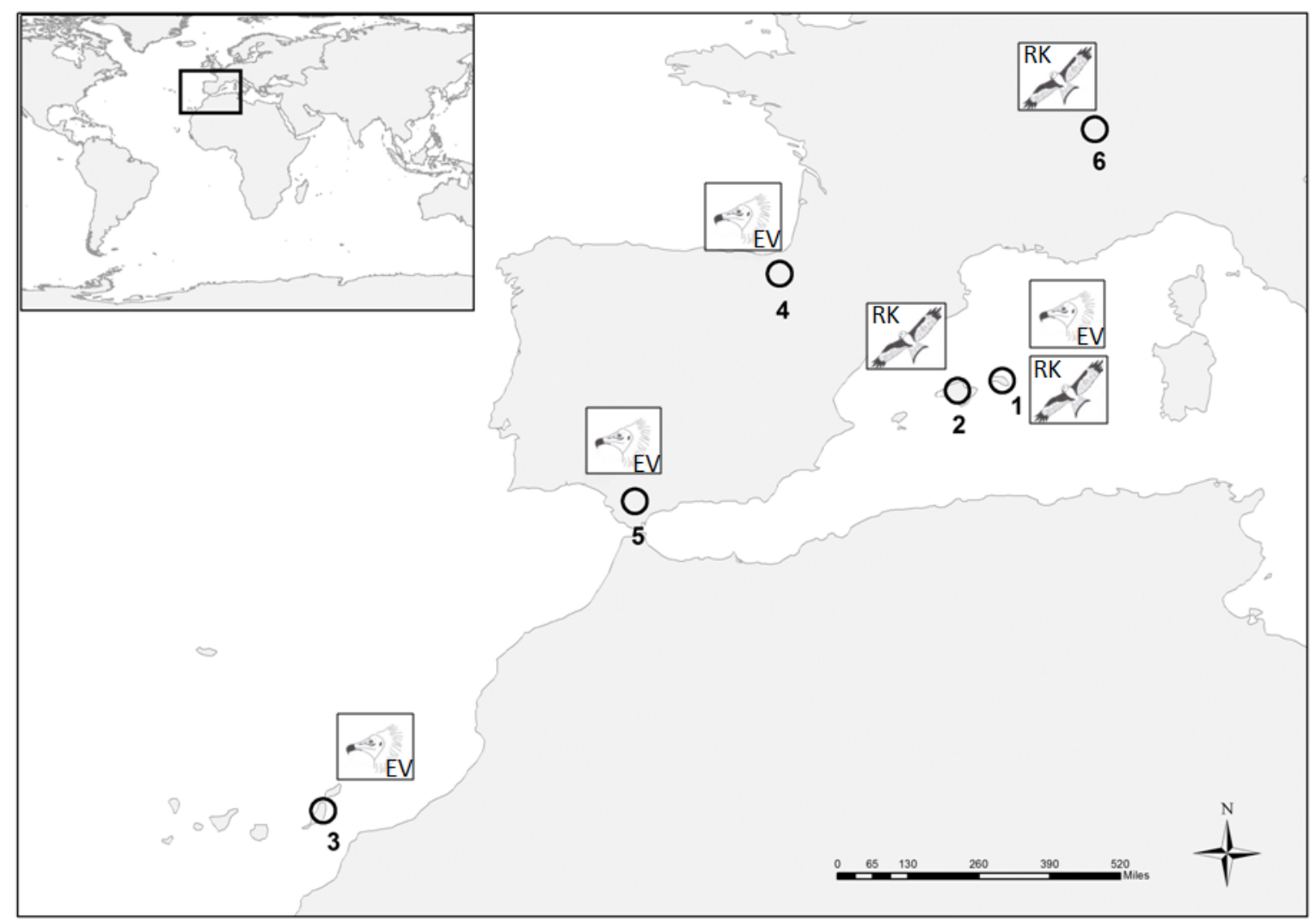

Figure 1 

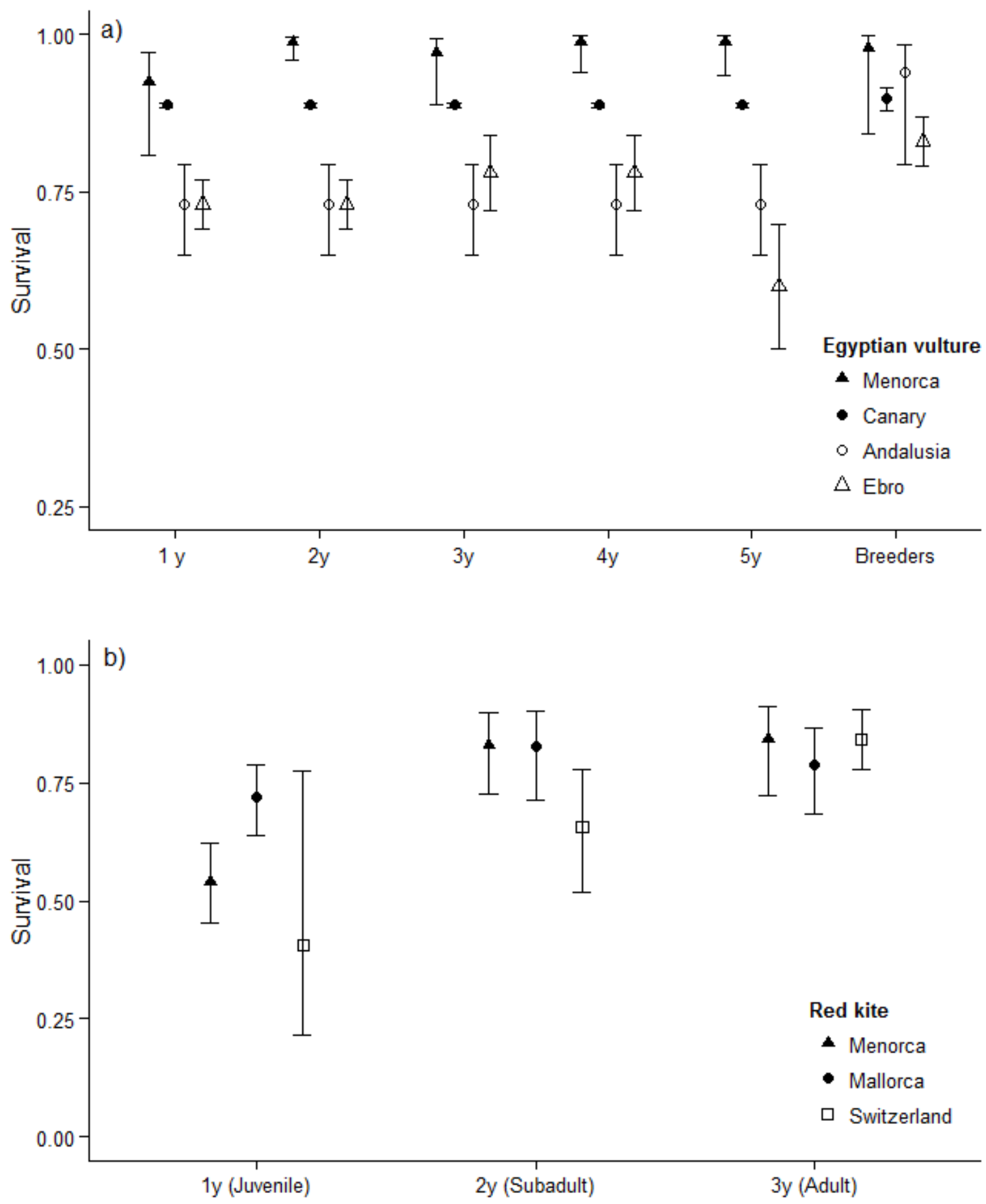

Figure 2 


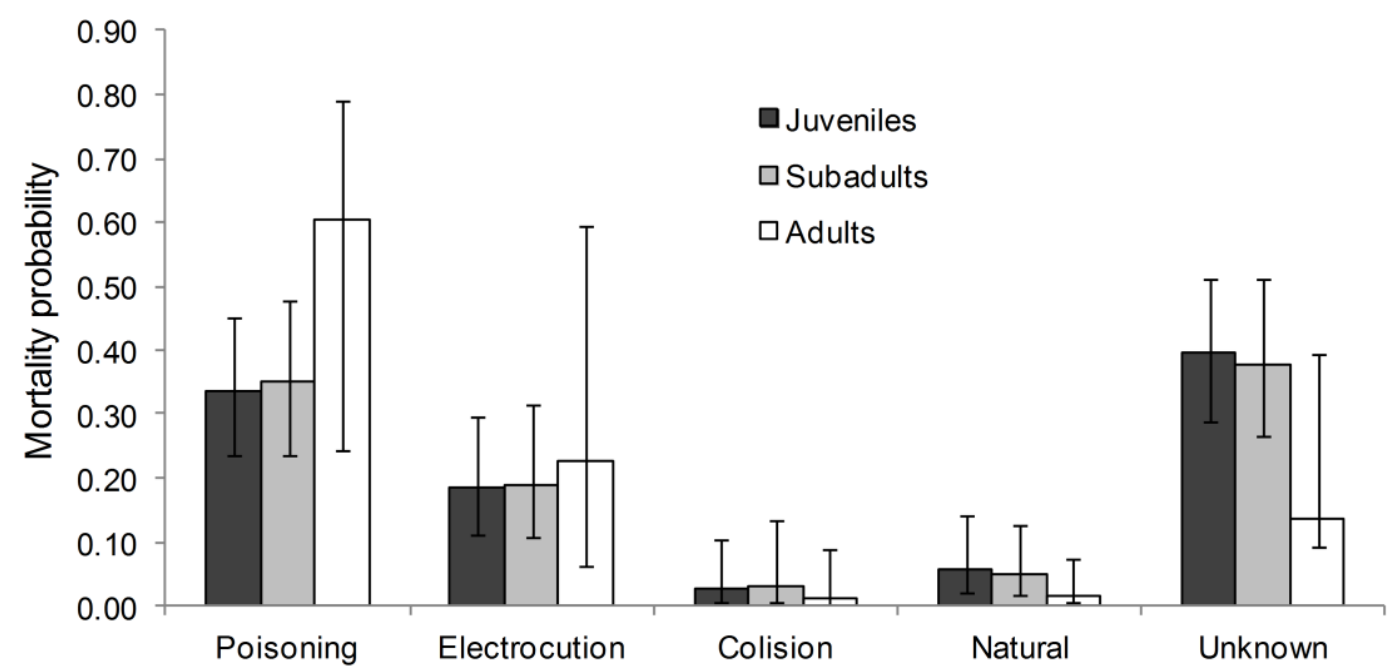

Figure 3 